\title{
Effect of Mental Disorders on the Mental Wellbeing of Prisoners in Kenya
}

\author{
Judith Museve ${ }^{1,2^{*}} \quad$ Charles H.O Angira ${ }^{1} \quad$ Peter J.O Aloka ${ }^{3}$ \\ 1.School of Health Sciences, Jaramogi Oginga Odinga University, P.O.BOX 210 , Code- 40601, Bondo, Kenya \\ 2.School of Health Sciences, Mount Kenya University, P. O. Box 342, Code- 01000, Thika, Kenya \\ 3.School of Education, Jaramogi Oginga Odinga University, P. O. Box 210, Code-40601, Bondo, Kenya
}

\begin{abstract}
This study investigated the effect of mental disorders on the mental wellbeing of prisoners in selected prisons in Kenya. A mixed method study design was employed in which quantitative and qualitative data was collected concurrently. A sample of 364 respondents was obtained using multistage sampling technique. The study used a structured questionnaire, Warwick-Edinburg Mental Wellbeing Scale (WEMWBS), MINI International Neuropsychiatric Interview, FGD and Key Informant Interview Schedules. Descriptive and inferential statistics were used to analyze quantitative data while thematic analysis was used to analyze qualitative data. The ANOVA test results indicated that mental disorders affect mental wellbeing of prisoners ( $p$-value $<0.0001$ ). Suicidality, panic disorder, PTSD and mood disorder with psychotic features were significantly associated with mental wellbeing at $\mathrm{p}=0.001, \mathrm{p}=0.015, \mathrm{p}=0.044$ and $\mathrm{p}=0.019$ respectively. The Kenya Prison Service management needs to establish comprehensive mental health services at all prisons as provided for in the Prisons Act for achievement of better mental wellbeing of prisoners.
\end{abstract}

Keywords: Effect; mental; wellbeing; disorder; prisoners; Kenya

DOI: $10.7176 /$ RHSS/10-14-02

Publication date:July $31^{\text {st }} 2020$

\section{Introduction}

Mental wellbeing includes good mental health and positive emotions; with high life satisfaction, sense of belonging and ability to cope with day-to-day life. Mental health is crucial to living a balanced healthy life as it determines one's decision making process and how they relate to other people in their lives. A mental disorder is an illness with significant psychological or behavioral manifestation that is associated with either a painful or distressing symptom or an impairment in functioning. As such, mental health is a key component of mental wellbeing yet mental disorders are a common health problem in prisons (Xiong, 2018). Several studies have established the prevalence of mental disorders among prisoners but there is paucity of research on the effect of mental disorders on the mental wellbeing of prisoners.

Prisons have been reported to have a high prevalence of mental disorders. Worldwide, it is estimated that about $20 \%$ of prisoners in jails have serious mental illness (Torrey, 2014). In England and Wales, nine (9) out of ten (10) prisoners had one or more of psychiatric disorders (ENAO, 2017). United States of America has $48 \%$ of inmates with mental health problems, with the leading disorders being depression and anxiety (Al Rousan et al, 2017). Canada has $73 \%$ of prisoners with mental disorders (Beaudette \& Stewart, 2016). Australia has $31 \%$ of prisoners with a mental disorder (Australian government Health Report, 2013). In Spain, 90.2\% of the prisoners have mental disorders (Zabala-Banos et al, 2016). In Brazil, 33.3\% of female and $12.9 \%$ of male prisoners had depression (Santos et al, 2019). India has $18.7 \%$ of prisoners with depression, $8 \%$ with anxiety and $8 \%$ with stress (Malik et al, 2019). Nigeria has $32.8 \%$ of offenders with depression (Agboola et al, 2017). In Uganda, $86 \%$ of prisoners have mental disorders with the leading disorder being depression (Forry et al, 2019).

Reports indicate that mental health problems are associated with increased chances of self- harm, suicide and reoffending. Mental disorders are risk factors for elevated suicide rates, premature mortality on release from prison and increased reoffending rates among prisoners (Fazel et al, 2016). In England, 70\% of the prisoners who committed suicide had mental health needs (ENAO report, 2017). This implies that the mental wellbeing of the prisoners has been compromised. While there may be diverse factors that influence mental wellbeing, mental disorders seemingly play a role yet mental health services in many prisons are inadequate. For example, in the USA less than half of the inmates with mental disorders had ever received treatment for their problem.

Kenya has a current prison population of 53348 prisoners spread over 105 penal institutions in the country (World Prison Brief, 2019). The Kenya Prisons Service has initiated a number of various programs that are implemented in varying degrees to provide purposeful activities for prisoners to reform and rehabilitate the offenders. However, the mental health services provided still lag behind. Despite the various interventions, many prisoners walk out of prison with psychological problems, with high chances of reoffending up to $70 \%$ (Mwenja, 2016). A study by Othieno showed that Kenyan prisoners have a variety of mental disorders with $22.5 \%$ with PTSD, 21.9\% OCD and 19.3\% Suicidality (Othieno, 2013). No research on the effect of mental disorders on mental wellbeing has ever been conducted in Kenya. The aim of this study was to investigate the effect of mental disorders 
on the mental wellbeing of prisoners in Kenya. The main objective was to establish the effect of mental disorders on mental wellbeing of prisoners in selected prisons in Kenya. Significantly, this study was done to its logical conclusion and identified the mental disorders that are significant predictors of mental wellbeing. Knowing the impact of mental disorders on mental wellbeing will serve to unveil the urgency of adequate mental health services for prisoners with targeted focus on the high risk mental disorders.

1.0 Problem statement

Mental health is a major component of mental wellbeing. Significant cases of mental disorders have been reported among prisoners in Kenya with an accompanying reoffending rate of $70 \%$. Although diverse factors may affect mental wellbeing, mental disorders are thought to play a key role in influencing mental wellbeing. Although a number of preventive and rehabilitation programs have been initiated in prisons, the establishment of mental health services still lags behind with little emphasis on its development. This compromises the prison mandate of correcting and rehabilitating offenders to become law abiding citizens. This study sought to establish the effect of mental disorders on the mental wellbeing of prisoners in selected prisons in Kenya.

\section{Methodology}

2.1: Study design

This study employed mixed method research design based on the Creswell model (Creswell, 2007). Both Quantitative and qualitative data was collected at the same time from different sources using different methods. The various data was converged for comparison, interrelation and validation of results. The study population was the prisoners at Nyeri maximum prison (men) and Langata women's prison (female). The two prisons have a collective population of 3200 inmates. The quantitative sample size was determined using the Krejcie \& Morgan sample size table criteria (Krejcie and Morgan, 1970). The table suggests the optimal sample size - given a specific population size, specific margin of error and a desired confidence interval. With population size of 3200 and using a confidence level of $95 \%$ and margin of error of 5\%, then the sample size is $\mathbf{3 4 6}$ prisoners. Adding a 5\% nonresponse rate gave a sample size of $\mathbf{3 6 4}$. The respondents are within a regulated environment thus a low nonresponse rate was anticipated. For the qualitative sample, there were 20 participants for FGDS, with 10 participants per FGD. Four (4) prison staff participated as KII, with two (2) staff per prison. The KII were with the prison Welfare Officer and head of the prison health facility of each prison. A screening questionnaire, Warwick Edinburg Mental Wellbeing Scale (WEMWBS) and MINI International Neuropsychiatric Interview (MINI) were used to gather data from inmates. Screening questionnaire was used to gather demographic data and historical background of the respondents, WEMWBS was used to measure level of mental wellbeing while MINI was used to assess respondents for common mental disorders.

\subsection{Data Analysis}

The data was analyzed using frequencies, percentages and standard deviation. Cross tabulation was done using Chi square test where $95 \%$ confidence interval was used to show associations and p-value $<0.05$ was considered a statistically significant level of precision. Comparison between groups was determined using ANOVA. Logistic regression was done to model mental disorders for the entire sample. Level of mental wellbeing, Prevalence of mental disorders and association between mental wellbeing and mental disorders were determined.

\section{Findings}

3.1 Level of mental wellbeing

The WEMWBS has 14 items that are used to determine the mental wellbeing of the prisoners. The total score was obtained by adding individual responses for the 14 mental wellbeing variables each with 1 to 5 value choices. The maximum score therefore is 70 and the minimum is 14. A WEMWBS score of less than 43.5 indicates a high risk of developing depressive symptom while a score higher than 43.5 indicates a low risk of developing depressive symptoms. The results on the level of mental wellbeing of prisoners are as shown in Table 1.

The results in Table 1 show that generally the prisoners had high level of mental wellbeing with $86.3 \%$ (314/364) having positive mental wellbeing. On the other hand, 13.7\% (50/364) of the prisoners had a total score of less than 43.5 , with female prisoners $(31.5 \%)$ being more likely to develop depressive symptoms than male prisoners $(8.8 \%)$ 
Table 1: Descriptive Statistics of total mental wellbeing score

\begin{tabular}{|l|l|l|}
\hline Statistic & Sex & Total Score \\
\hline \multirow{2}{*}{ N } & Male & 284 \\
\cline { 2 - 3 } & Female & 80 \\
\hline Prisoner score more than 43.5 & Male & $239(91.2)$ \\
& Female & $55(68.5)$ \\
\hline Prisoner score less than 43.5 & Male & $25(8.8)$ \\
& Female & $25(31.5)$ \\
\hline Missing & Male & 0 \\
\cline { 2 - 3 } & Female & 0 \\
\hline Minimum & Male & 26.0 \\
\cline { 2 - 3 } & Female & 19.0 \\
\hline Maximum & Male & 70.0 \\
\cline { 2 - 3 } & Female & 70.0 \\
\hline
\end{tabular}

The summative responses to the individual WEMWBS items are summarized in Table 2. The leading positive feelings were: Feeling optimistic about the future (72.8\%), Feeling useful $(72.8 \%)$, Thinking clearly $(73.7 \%)$, Feeling close to other people (70.4\%), Able to make up their own mind (78.0\%) and Being interested in new things (77.5\%). The prisoners were less likely to report: Feeling relaxed (49.7\%) and Feeling cheerful $(54.6 \%)$. Generally, male prisoners had better mental wellbeing than female prisoners. However, this finding differed with the views of the FGD discussants who felt that prisoners had low mental wellbeing. They cited the reasons for low mental wellbeing as confinement, mental disturbance, stress, worry, anxiety and concerns about the future. This was in contrast to the actual mental wellbeing scores which indicated high level of mental wellbeing. The FGD discussants were convinced that the positive feelings were caused by increased chances of release, prison programs, skills learning, time for reflection, improved prison services and the positive attitude of the prison staff. They observed that changes in the prison policy had increased their chances of being released thus giving them hope for the future. Further, they unanimously agreed that the prison programs enabled them to learn new skills which made them feel useful and also kept them busy thus preventing negative thoughts. In the words of one female FGD discussant, "The programs keep you busy so you do not have a lot of thinking, which reduces stress. You also work and talk with the other people which makes you feel you are not the only one with problems". Yet another female discussant opined that, "This programs are useful for getting yourself out of prison. With certificates for skills training, its easy to be released or have your time reduced when you apply for resentencing. A male FGD discussant attributed their state of positivity to the friendly attitude of the prison staff. In their own words they said," The prison is much better this days. The staff are friendly and listen to you and that makes life better". 
Table 2: Level of mental wellbeing of the prisoners

\begin{tabular}{|c|c|c|c|c|c|c|c|c|c|}
\hline \multirow{2}{*}{$\begin{array}{l}\text { Mental } \\
\text { wellbeing } \\
\text { statement }\end{array}$} & \multicolumn{3}{|c|}{ Male $\mathrm{n}(\%)$} & \multicolumn{3}{|c|}{ Female n (\%) } & \multicolumn{3}{|c|}{ Total n (\%) } \\
\hline & 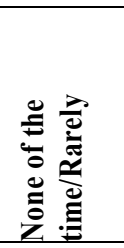 & 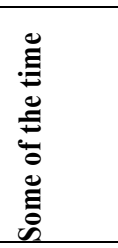 & 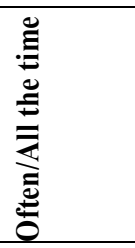 & 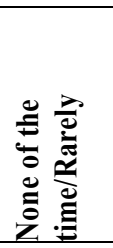 & 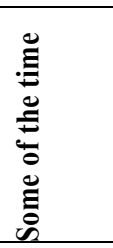 & 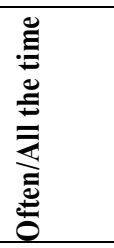 & 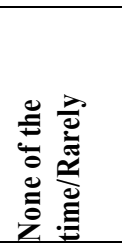 & 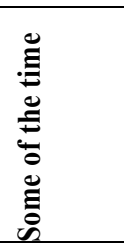 & 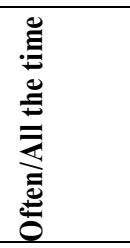 \\
\hline $\begin{array}{l}\text { I've been } \\
\text { feeling } \\
\text { optimistic }\end{array}$ & $19(6.8)$ & $43(15.2)$ & $221(78.1)$ & $11(14.3)$ & $25(32.5)$ & $41(53.3)$ & $30(8.3)$ & $68(18.9)$ & $262(72.8)$ \\
\hline $\begin{array}{l}\text { I've been } \\
\text { feeling useful }\end{array}$ & $20(7.1)$ & $36(12.8)$ & $226(80.2)$ & $26(33.4)$ & $16(20.5)$ & $36(46.2)$ & $46(12.8)$ & $52(14.4)$ & $262(72.8)$ \\
\hline $\begin{array}{l}\text { I've been } \\
\text { feeling relaxed }\end{array}$ & $57(20.2)$ & $70(24.8)$ & $155(55.0)$ & $33(42.3)$ & $21(26.9)$ & $24(30.7)$ & $90(25.0)$ & $91(25.3)$ & $179(49.7)$ \\
\hline $\begin{array}{l}\text { I've been } \\
\text { feeling } \\
\text { interested in } \\
\text { other people }\end{array}$ & $15(5.4)$ & $46(16.4)$ & $220(78.3)$ & $24(30.1)$ & $30(37.5)$ & $26(32.6)$ & $39(10.8)$ & $76(21.1)$ & $246(68.2)$ \\
\hline $\begin{array}{l}\text { I've had energy } \\
\text { to spare }\end{array}$ & $30(10.7)$ & $33(11.7)$ & $218(77.6)$ & $28(35.9)$ & $21(26.9)$ & $29(37.2)$ & $58(16.2)$ & $54(15.0)$ & $247(68.8)$ \\
\hline $\begin{array}{l}\text { I've been } \\
\text { dealing with } \\
\text { problems well }\end{array}$ & $12(4.2)$ & $51(18.1)$ & $219(77.7)$ & $20(26.0)$ & $28(36.4)$ & $29(37.7)$ & $32(8.9)$ & $79(22.0)$ & $248(69.1)$ \\
\hline $\begin{array}{l}\text { I've been } \\
\text { thinking clearly }\end{array}$ & $10(3.5)$ & $51(18.1)$ & $221(78.4)$ & $15(20.0)$ & $18(24.0)$ & $42(56.0)$ & $25(7.0)$ & $69(19.3)$ & $263(73.7)$ \\
\hline $\begin{array}{l}\text { I've been } \\
\text { feeling good } \\
\text { about myself }\end{array}$ & $26(9.2)$ & $56(19.9)$ & $200(70.9)$ & $21(26.6)$ & $23(29.1)$ & $35(44.3)$ & $47(13.0)$ & $79(21.9)$ & $235(65.1)$ \\
\hline $\begin{array}{l}\text { I've been } \\
\text { feeling close to } \\
\text { other people }\end{array}$ & $16(5.7)$ & $52(18.3)$ & $216(76.0)$ & $15(19.2)$ & $24(30.8)$ & $39(50.0)$ & $31(8.6)$ & $76(21.0)$ & $255(70.4)$ \\
\hline $\begin{array}{l}\text { I've been } \\
\text { feeling } \\
\text { confident }\end{array}$ & $16(5.7)$ & $52(18.5)$ & $213(75.8)$ & $20(25.7)$ & $23(29.5)$ & $35(44.9)$ & $36(10.0)$ & $75(20.9)$ & $248(69.1)$ \\
\hline $\begin{array}{l}\text { I've been able } \\
\text { to make up my } \\
\text { mind about } \\
\text { things }\end{array}$ & $13(4.6)$ & $39(13.7)$ & $232(81.7)$ & 11(13.8) & $17(21.3)$ & $52(65.0)$ & $24(6.6)$ & $56(15.4)$ & $284(50.3)$ \\
\hline $\begin{array}{l}\text { I've been } \\
\text { feeling loved }\end{array}$ & $37(13.0)$ & $57(20.1)$ & $190(66.9)$ & $29(36.3)$ & $17(21.3)$ & $34(42.5)$ & $66(18.2)$ & $74(20.3)$ & $224(61.6)$ \\
\hline $\begin{array}{l}\text { I've been } \\
\text { interested in } \\
\text { new things }\end{array}$ & $14(5.0)$ & $32(11.3)$ & $238(83.8)$ & $19(23.8)$ & $17(21.3)$ & $44(55.0)$ & $33(9.1)$ & $49(13.5)$ & $282(77.5)$ \\
\hline $\begin{array}{l}\text { I've been } \\
\text { feeling cheerful }\end{array}$ & $57(20.0)$ & $62(21.8)$ & $165(58.1)$ & $26(32.9)$ & $20(25.3)$ & $33(41.8)$ & $83(22.9)$ & $82(22.6)$ & $198(54.6)$ \\
\hline
\end{tabular}

\subsection{Mental status of respondents}

The prisoners were assessed for specified mental disorders to establish their mental status and the results are as shown in Table 3. The results indicate a high prevalence of mental disorders whereby $63.2 \%$ of the prisoners manifested a mental disorder. The leading mental disorders are depression at $34.3 \%$, suicidality at $22 \%$ and mood disorder with psychotic features at $17.3 \%$. The least mental disorders are panic disorder and dysthymia. Generally, there were very low cases of Alcohol abuse and psychoactive drug use disorder among the prisoners. This finding is in agreement with the view of FGD discussants who were convinced that all prisoners were at high risk of mental disorder. As one female FGD member opined, "Here we are all at high risk of mental disorder. There is the shock of being convicted, lack of freedom, long prison term, too much thinking and worry". 
Table 3: Mental Status of the prisoners

\begin{tabular}{|l|l|l|}
\hline Mental disorder & Total (n ) & \% (N=364) \\
\hline Prisoner manifested a mental disorder & 230 & 63.2 \\
\hline Depression & 125 & 34.3 \\
\hline Dysthymia & 7 & 1.9 \\
\hline Suicidality & 80 & 22.0 \\
\hline Manic Episode & 25 & 6.9 \\
\hline Panic disorder & 7 & 1.9 \\
\hline Social Phobia & 19 & 5.2 \\
\hline OCD & 15 & 4.1 \\
\hline PTSD & 14 & 3.8 \\
\hline Alcohol abuse and dependence & 11 & 3.0 \\
\hline Psychoactive drug use disorders & 6 & 1.6 \\
\hline Mood disorder with psychotic features & 63 & 17.3 \\
\hline Psychotic disorders & 35 & 9.6 \\
\hline Generalized Anxiety Disorder & 9 & 2.5 \\
\hline Antisocial Personality Disorder & 63 & 17.3 \\
\hline
\end{tabular}

3.3 Association between mental disorders and mental wellbeing

The study established a linear regression model to ascertain whether the mental disorders can cause variation in the level of mental wellbeing. This was done by use of standard multiple regression analysis, where aspects of mental disorders were factored in the model at once and the results are as shown in Table 4.

Table 4: Regression Analysis Model summary output: Contribution of Mental disorders on Variance of mental wellbeing

\begin{tabular}{|l|l|l|l|l|l|l|l|l|}
\hline $\mathrm{R}$ & R Square & Adjusted R Square & Std. Error of the Estimate & \multicolumn{4}{l|}{ Change Statistics } \\
\cline { 5 - 7 } & & & R Square Change & F Change & df1 & df2 & Sig. F Change \\
\hline $0.3340 .111^{\mathrm{a}}$ & 0.078 & 10.094 & 0.111 & 3.376 & 13 & 350 & $<0.0001$ \\
\hline
\end{tabular}

a. Predictors: Depression, Dysthymia, Suicidality, Manic episode, Panic disorder, Social phobia, OCD, PTSD, Alcohol abuse \& dependence, Psychoactive drug use disorders, Mood disorders with psychotic features, Psychotic disorders, Generalized anxiety disorder, Antisocial personality disorder.

The $R$ value of 0.334 indicates a weak level of the prediction, but it is significant $(p<0.0001)$. The value of Adjusted R Square (0.078) expressed as a percentage shows how much of the variance in mental wellbeing was explained by mental disorders. Thus the mental disorders account for $7.8 \%$ of the variation in mental wellbeing. This means that mental disorders cause variation in mental wellbeing.

To assess whether the variation was significant, One -Way ANOVA was used to test the null hypothesis that mental wellbeing does not vary significantly across the different mental disorders and the results are shown in Table 5 below.

$\mathrm{H}^{0}$ : There is no statistical relationship between mental disorder and mental wellbeing Table 5: ANOVA- Influence of Mental Disorders on Mental Wellbeing

\begin{tabular}{|l|l|l|l|l|l|}
\hline Source of variation Model & Sum of Squares & Df & Mean Square & F-value & P-value. \\
\hline Regression & 4860.368 & 14 & 347.169 & 3.435 & $<0.0001$ \\
$1 \quad$ Residual & 35271.071 & 349 & 101.063 & & \\
Total & 40131.440 & 363 & & & \\
\hline
\end{tabular}

Dependent Variable: Mental Well Being

Predictors / Independent variables : Constant, Depression, Dysthymia, Manic episode, Suicidality, Panic disorder, Social phobia, OCD, PTSD, Mood disorder with psychotic features, Psychotic disorders, Alcohol abuse and dependence, Psychoactive drug use disorders, Generalized anxiety, Antisocial personality disorder.

The results in Table 5 above show that the mental disorders statistically significantly predict the level of mental wellbeing $(\mathrm{p}<0.0001)$. This demonstrates that there is a statistically significant difference in the level of mental wellbeing across mental disorders, and we reject the null hypothesis at $95 \%$ confidence limits. It was concluded that there is a significant relationship between mental disorder and the level of mental wellbeing.

To evaluate the contribution of each of the mental disorders on the variation in mental wellbeing, linear regression analysis was employed to get the coefficient outputs. The variable mental wellbeing was regressed in a robust linear regression model against variables measuring mental disorder and the coefficient, $\mathrm{p}$-values and $95 \%$ confidence interval of the coefficient are presented in Table 6 below. The beta value gives the unique variance in the level of mental wellbeing accounted for by each mental disorder with the contribution of the others held constant. 
Table 6. Linear Regression - Influence of Mental Disorder on Metal Wellbeing of prisoners in Kenya.

\begin{tabular}{|c|c|c|c|c|c|c|c|}
\hline & \multicolumn{2}{|c|}{$\begin{array}{l}\text { Unstandardized } \\
\text { Coefficients }\end{array}$} & \multirow{2}{*}{$\begin{array}{l}\text { Standardized } \\
\text { Coefficients } \\
\text { Beta }\end{array}$} & \multirow[b]{2}{*}{$\mathrm{T}$} & \multirow[b]{2}{*}{ Sig. } & \multicolumn{2}{|c|}{$\begin{array}{l}\text { 95.0\% Confidence } \\
\text { Interval for B }\end{array}$} \\
\hline & B & Std. Error & & & & $\begin{array}{l}\text { Lower } \\
\text { Bound }\end{array}$ & $\begin{array}{l}\text { Upper } \\
\text { Bound }\end{array}$ \\
\hline (Constant) & 63.401 & 3.376 & & 18.781 & .000 & 56.762 & 70.041 \\
\hline Depression & 2.868 & 1.462 & .217 & 1.962 & .051 & -.008 & 5.744 \\
\hline Dysthymia & 1.100 & 3.769 & .051 & .292 & .771 & -6.313 & 8.512 \\
\hline Suicidality & 5.504 & 1.396 & .371 & 3.943 & .000 & 2.759 & 8.250 \\
\hline Manic Episode & 2.763 & 2.274 & .146 & 1.215 & .225 & -1.711 & 7.236 \\
\hline Panic disorder & -10.691 & 4.156 & -.494 & -2.573 & .011 & -18.864 & -2.518 \\
\hline Social Phobia & 4.013 & 2.703 & .204 & 1.485 & .139 & -1.303 & 9.329 \\
\hline OCD & -2.736 & 3.048 & -.135 & -.898 & .370 & -8.731 & 3.258 \\
\hline PTSD & 5.820 & 2.914 & .284 & 1.997 & .047 & .088 & 11.551 \\
\hline Alcohol abuse & -7.354 & 3.861 & -.352 & -1.905 & .058 & -14.948 & .239 \\
\hline Psychoactive drug abuse & .120 & 4.487 & .005 & .027 & .979 & -8.705 & 8.944 \\
\hline $\begin{array}{l}\text { Mood disorder with } \\
\text { psychotic features }\end{array}$ & -3.603 & 1.691 & -.230 & -2.131 & .034 & -6.928 & -.278 \\
\hline Psychotic disorders & -3.005 & 1.789 & -.169 & -1.679 & .094 & -6.524 & .514 \\
\hline $\begin{array}{l}\text { Generalized Anxiety } \\
\text { Disorder }\end{array}$ & 1.606 & 3.183 & .076 & .505 & .614 & -4.653 & 7.866 \\
\hline $\begin{array}{l}\text { Antisocial Personality } \\
\text { Disorder }\end{array}$ & .689 & 1.555 & .044 & .443 & .658 & -2.370 & 3.747 \\
\hline
\end{tabular}

From Table 6, the constant value of the model is 63.401 with a confidence interval of [56.762, 70.041]. This implies that most prisoners will present about 63.401 units of level of mental wellbeing before factoring in mental disorders. It is evident the different mental disorders contributed differently in influencing the level of mental wellbeing among prisoners. From this analysis; suicidality, panic disorder, PTSD and mood disorder with psychotic features were significant predictors of mental wellbeing. Absence of suicidality increased mental wellbeing by $.371(\mathrm{p}$-value $=0.001)$, presence of panic disorder lowered mental wellbeing by $.494(\mathrm{p}$-value $=$ $0.015)$, absence of PTSD increased mental wellbeing by $.284(\mathrm{p}$-value $=0.044)$ and presence of mood disorder with psychotic features lowered mental wellbeing by $.230(\mathrm{p}$-value $=0.019)$. Panic disorder had the greatest impact on mental wellbeing while Mood disorder with psychotic features had the least impact when all the independent variables are put together.

\section{Discussion}

4.1 Demographic characteristics of the respondents

A sample size of 364 respondents was used. There was 100\% response rate, lending the findings credence. A large majority of the respondents were male. Majority of the prisoners were young adults with a mean age of 38 years. Most of the prisoners had primary school level of education followed by secondary school education. There were more males than females with primary school level of education, but more females than males with secondary school education, middle level college education and university education. Generally, fewer females than males dropped out of school or never went to school. Majority of male prisoners were married while majority of the female prisoners were single. Majority of the prisoners were Protestants or Catholics. A significant number of prisoners had no religious affiliation.

\subsection{Level of mental wellbeing}

The study established that majority of the prisoners had high level of mental wellbeing at $86.3 \%$. The change in prison policy to allow resentencing with chances of a reviewed sentence provided great hope for release thus making them optimistic. It can be hypothesized that the prisoners are happier because of increased chances of release from prison. Likewise, the new skills learnt gave the prisoners hope of being self-reliant and improved prison services gave them some peace of mind. This finding resonates with the Scottish prison service reports $(2013,2017)$ that improved prison services improved the mental wellbeing of prisoners. In addition, this resonates with the report of Garcia-vita et al (2017) that positive mental wellbeing is experienced with less drug use. However, this finding was in contrast with the view of the FGD discussants who felt that inmates had low levels of mental wellbeing with little possibility of being relaxed or cheerful. They cited things that affected mental wellbeing negatively as confinement, slow resolution of appeals, mental disturbance, stress, worry, anxiety and concerns about the future. Indication of confinement as cause for low mental wellbeing confirmed that incarceration had a negative psychological impact on prisoners. Generally, males had higher levels of mental 
wellbeing than females. This finding resonates with the Scotland Prison Survey (2013) which reported that more male than female prisoners felt optimistic, relaxed and good about themselves. The finding is supported by those of a similar study done in Nigeria that reported female prisoners having lower levels of mental wellbeing than male prisoners (Ebeh et al, 2019).

4.3 Mental status of prisoners

The study established that there is a high prevalence of mental disorders among prisoners, at $63.2 \%$. The leading mental disorders are depression, suicidality and mood disorder with psychotic features. There is a decrease in mental disorders compared to the findings of Zabala-Banos et al (2016) who reported that prisoners had a mental disorder prevalence of $90.2 \%$. Likewise, it is decline from the finding of Forry et al (2019) which showed that there was a mental disorder prevalence of $86.0 \%$ among prisoners. However, the prevalence is higher than that reported by Malik et al (2016) that prevalence of depression among prisoners was $18.5 \%$. The decline in mental disorders can be attributed to improved prison services and friendlier prison staff. The finding on the leading mental disorder was in agreement with the findings of previous studies which cited depression as the main mental disorder among prisoners (Santos et al, 2019; Malik et al, 2016). However, the findings vary from those of Othieno (2013) who reported the leading mental disorder as PTSD. Similarly, Tung et al (2018) reported the leading disorder as anxiety.

4.4 Influence of mental disorders on mental wellbeing

The study established that there was a statistically significant relationship between mental disorders and the level of mental wellbeing of prisoners. One way ANOVA test confirmed that indeed the level of mental wellbeing varies significantly across mental disorders. The presence of a mental disorder lowered the level of mental wellbeing. It was established that suicidality, panic disorder, PTSD and mood disorder with psychotic features are significant predictors of the level of mental wellbeing. Panic disorder had the greatest impact on mental wellbeing while mood disorder with psychotic features had the least impact. The fact that mental disorders accounted for only $7.8 \%$ of the variation in mental wellbeing indicates that there are other factors influencing about $92 \%$ of mental wellbeing. These other factors likely to influence mental wellbeing include moderating effects and extrinsic variables whose effects were not totally excluded. These other factors include the prison policy, prison programs, individual attitude and attitude of the prison staff. However, $7.8 \%$ is a significant effect hence there is need for establishment of structures to address the mental disorders for achievement of better mental wellbeing of prisoners.

\section{Conclusion}

The study reported a high level of mental wellbeing among prisoners. There is a high prevalence of mental disorders among the prisoners with prisoners being at high risk of depression and suicidality. It established that mental disorders significantly influence the mental wellbeing of prisoners with the presence of a mental disorder lowering the level of mental wellbeing. Suicidality, panic disorder, PTSD and mood disorder with psychotic features are significant predictors of mental wellbeing. It can be concluded that mental disorders acts as a barrier to mental wellbeing thus hindering the rehabilitation of afflicted prisoners.

\section{Recommendations}

There is need for the full implementation of the mental health services as provided for in the Prisons Act at all prisons for achievement of better mental wellbeing of prisoners. This will enhance the success of prison rehabilitation programs.

\section{References}

Agboola A, Babalola E \& Udofia O. (2017). Psychopathology among Offenders in a Nigeria Prison. International Journal of Clinical Psychiatry 2017, 5(1): 10-15. DOI: 10.5923/j.ijcp.20170501.02

Al-Rousan, Tala, Rubenstein, Linda, Bruce Sieleni, Harbans, Deol, and Robert, B Wallace. (2017). Inside the nation's largest mental health institution: a prevalence study in a state prison system. BMC Public Health 17, 342 (2017). https://doi.org/10.1186/s12889-017-4257-0.

Beaudette, J. N., \& Stewart, L. A. (2016). National Prevalence of Mental Disorders among Incoming Canadian Male Offenders. Canadian journal of psychiatry. 61(10), 624-632. https://doi.org/10.1177/0706743716639929

Creswell, John. W. (2007). Research design: Qualitative, quantitative, and mixed methods approaches (2nd ed.). Thousand Oaks, CA: Sage.

Ebeh, R. Ebireonwu, Annorzie, H. Ihuoma and Mbagwu, M. Ifeoma. 2019. Jail Term Length, Gender and Age as Determinants of Psychological Distress Among Prison Inmates in Owerri. Journal of Social Sciences and Humanities Vol. 5, No. 3, pp. 321-327. http://www.aiscience.org/journal/jssh

Fazel, Seena, and Seewald, Katharina. (2012). Severe mental illness in 33588 prisoners worldwide: systematic 
review and metaregression analysis. The British Journal of Psychiatry (2012) 200, 364-373. doi: 10.1192/bjp.bp.111.096370l

Fazel, S., Hayes, A., Bartellas, K., Clerici, M \& Trestman, R. (2016). The mental health of prisoners: A review of prevalence, adverse outcomes and interventions. Lancet Psychiatry. 2016 September; 3(9): 871-881. doi:10.1016/S2215-0366(16)30142-0

Forry J.B., Ashaba S. \& Rukundo G.Z. (2019). Prevalence and associated factors of mental disorders among prisoners in Mbarara municipality, southwestern Uganda: a cross-sectional study. BMC Psychiatry (2019) 19:178 https://doi.org/10.1186/s12888-019-2167-7

Krejcie, Robert V. and Morgan, Daryle W. (1970). Determining Sample Size for Research Activities. Educational and Psychological Measurement, 30, 607-610.

Mwenja, Irungu. (2016). It is punishment not rehabilitation in our prisons? https://www.standardmedia.co.ke/ureport/article/2000210941/it-is-punishment-not-rehabilitation-in-ourprisons.

National Mental Health Report 2013, Australia. Indicator 20a: Prevalence of mental illness among people who are remanded or newly sentences to adult correctional facilities. Page last updated: 2013

National Audit Report of England, June 2017

Othieno, C. (2013). Prevalence of mental disorders among convicted Adult offenders in Kenyan correctional Institutions. www.prawa.org/wp-content/uploads/2013/06/Adults-Kenya.pptx

Santos MM, Santos Barros CR \& Andreoli SB.(2019). Correlated factors of depression among male and female inmates. Revista Brasileira de Epidemiologia,22, e190051. Epub September 23, 2019.https://doi.org/10.1590/1980-549720190051.

Tung T, Hsiao Y, Shen S and Huang C.(2018). The prevalence of mental disorders in Taiwanese prisons: A nationwide population - based study. Soc Psychiatry Psychiatr Epidemiol 2018; 54(3):379-386.

Torrey EF, Zdanowicz MT, Kennard AD et al, (2014). The treatment of persons with mental illness in prisons and jails: A state survey. Arlington, VA, Treatment Advocacy Center, April 8, 2014.

Xion G. 2018. Why it is important to care for your Mental Health. Blog.doctorondemand.com/why-it-is-importantto-care-for-your-mental-health-834c8670b889

Zabala-Banos MC, Segura A, Maestre-Miquel, Martinez-Lorca, Rodriguez-Martin, Romero D \& Rogriguez M. (2016). Mental disorder prevalence and associated risk factors in three prisons of Spain. Rev Esp Sanid Penit 2016; $18: 13-23$ 